15) H. Freiser : 本誌, 21, 1300 (1972).

16) H. Irving, R. J. P. Williams : J. Chem. Soc., 1953, 3192.

$$
\stackrel{\imath}{s}
$$

Stability constants of 2, 3-dimethyl-5-hydroxyquinoxaline and 1-hydroxy-6, 7, 8, 9-tetrahydrophenazine metal chelates. Yoshinori KIDANI, Kenji INAGak. * and Hisashi KoIKE** (*Faculty of Pharmaceutical Sciences, Nagoya City University, 3-1, Tanabe-dori, Mizuho-ku, Nagoya-shi, Aichi; **School of Medical Technology and Nursing, Fujita Gakuen University, Kutsukake-cho, Toyoake-shi, Aichi) 2, 3-Dimethyl-5-hydroxyquinoxaline (5-OH-DMQx) and 1-hydroxy-6, 7, 8, 9-tetrahydrophenazine (1-OHTphz) have been synthesized. The acid dissociation constants of these ligands and the stability constants of their metal chelates have been measured in $50 \%$ (v/v) water-ethanol solution. The values obtained have been compared with those of 5-hydroxyquinoxaline and 2-substituted oxine metal chelates. The $\mathrm{p} K_{\mathrm{OH}}$ values of 5-OH-DMQx and 1-OH-Tphz are 9.98 and 10.01 , respectively. These values are considerably larger than the corresponding constant of 5-hydroxyquinoxaline, 9.29.

As to the metal chelate stability constants, (a) the metal chelate stability order is as follows : 5-OHDMQx; $\log K_{1} \mathrm{Cu}>\mathrm{Zn}>\mathrm{Co}>\mathrm{Ni}>\mathrm{Cd}$ and $\log \beta_{2} \mathrm{Cu}$ $>\mathrm{Co}>\mathrm{Zn}>\mathrm{Ni}>\mathrm{Cd}$. 1-OH-Tphz; $\log K_{1} \mathrm{Cu}>\mathrm{Zn}>$ $\mathrm{Co} \approx \mathrm{Ni}>\mathrm{Cd}$ and $\log \beta_{2} \mathrm{Cu}>\mathrm{Co}>\mathrm{Ni} \approx \mathrm{Zn}>\mathrm{Cd}$. (b) the stability constants of these metal chelates are smaller than the corresponding constants of 5-hydroxyquinoxaline, regardless of the value of $\mathrm{p} K_{\mathrm{OH}}$ with the exception of the $\mathrm{Zn}$-chelates. (c) The difference of the stability constants among $\mathrm{Co}_{-}, \mathrm{Ni}-$ and $\mathrm{Zn}-$ chelates is less than $0.4 \log$ unit. The behavior of the stability constants of 5-OH-DMQx and 1-OH$\mathrm{Tphz}$ indicates the similar tendency to that of 2substituted oxine metal chelates. Accordingly, the stability constants of these metal chelates have been explained in terms of steric hindrance.

(Received Oct. 14, 1974)

\section{Keywords}

Hydroxyquinoxaline

Hydroxyphenazine

Metal chelate

Stability constant

Steric hindrance

\title{
けい光 $\mathbf{X}$ 線スペクトル強度式における一次 $\mathbf{X}$ 線寄与率と 定量分析への応用
}

\author{
石来送子* \\ (1974 作 8 月 30 日受理)
}

\begin{abstract}
けい光X線によるルーティン分析は，よく管理された検量線に基づいて実施されるが，ての作業工程 にのらないような種々雑多な試料の分析を行うため, 簡単で新しい方法として, 管球からの一次X線を 数本のスペクトルと仮定して，それぞれの寄与率を求め，乙れをけい光 $\mathrm{X}$ 線スペクトル強度式に導入 し，式を単純化し，定量分析する方法を検討した。例として，銅，鉄，チタン，スズのスペクトルにつ いて，実験により一次 $\mathrm{X}$ 線寄与率と各元素に特有な定数項を求め，フルミニウム合金，ホワイトメタ ル，銅合金などの分析に利用した結果を示した. 含有量が $1 \%$ 末満のものの分析では誤差が大きく, 分 析值の厳密な正確性は望めないが, 含有量の大きいものについては, 均質試料であれば, 迅速に, 簡単 に，元素の定量を行うことが可能である.
\end{abstract}

$$
1 \text { まえがき }
$$

けい光X線分析法は，精度，感度，安定性など，装置 に起因する問題点が非常に少なくなったことから，材質

*鉄道技術研究所：東京都国分寺市光町
分析の分野で最も普及した分析法の一つであり，紬成の 類似した試料の規格值の検定などには，最も威力を発捙 してきた.ところが最近になって，このような材質分析 より，むしろ各種材料の設置環境との相互作用による表 面污染物, 表面生成物, あるいは䇢しい環境に対処しう 
るように開発された新材料など，組成も種々雑多で，ま だ検星線が用意されていないものに対する分析の要請が 大きくなりつつある.このような試料に対しては，分析 值の流密在正確性より, 分析の正速性, データの求めや 与さなよ゙が優先する場合が多い，このような観点から， この報毕は，よく管理された検量線に基づいて実施され るルーティン分析からは始た雑多な試料に関する分析 法を亦したものである。

過卡卜数乍来, 忛光X線分析法は, 標隼試料省数多 く準薉してそれとの比較測定という経験的，実験的方法 が流であのたが，それと併行して，次に示すような， (iillam 及び Heal1)，Sherman ${ }^{2)}$ らによる均質系試料に 打けるX線渱度式（1）在基本として，測定されたスペ クトル強度から計算により試料の組成を求めようと，い ろいろ原多力がなさ叔てきた。

$$
\begin{gathered}
I_{\mathrm{A}}=\operatorname{cosec} \phi_{2} \int_{\lambda_{\mathrm{m}}}^{\lambda_{\mathrm{A}}} \frac{Q_{\mathrm{A}}(\lambda) \cdot W_{\mathrm{A}} \cdot I_{0}(\lambda)}{\mu_{0}(\lambda) / \rho \cdot \operatorname{cosec} \phi_{1}+\mu_{\mathrm{A}} / \rho \cdot \operatorname{cosec} \phi_{2}} \mathrm{~d} \lambda \\
Q_{\mathrm{A}}(\lambda)=\mu_{0}{ }^{\mathrm{A}}(\lambda) / \rho \cdot K_{\mathrm{A}} \cdot \omega_{\mathrm{A}} \cdot R_{\mathrm{A}}
\end{gathered}
$$

（式けの記号については，Table 1 に記載した.）実際 には，一次X線強度の波佥分布汸不明であったために， 一次X線空単色光と仮定し，試料を一部希釈したり ${ }^{3)}$, 一.重希釈4)，2 種類の希釈剂の使用5)などにより，一次 X線強度に闒連する項を消去するやり方, 取り出儿何在 変化させつつ一次 $\mathrm{X}$ 線の平均波長学求め，乙れをX線強 度式に尊入与る方法 ${ }^{6)}$, 及び，測定成分元素の吸収端よ りわずかに短波厓側を最大有効エネルギーとし，入射 $\mathrm{X}$ 線エネルギーはずでてこに単色化されていると仮定す ろ. Stephenson の方法7)などが検討された。しかし，有

\begin{tabular}{|c|c|}
\hline$I_{\mathrm{A}}$ & : The characteristic $x$-ray intensity of element $A$ \\
\hline$I_{0}(\lambda)$ & : The primary $\mathbf{x}$-ray intensity at wavelength $\lambda$ \\
\hline$\phi_{1}$ & $\begin{array}{l}\text { The angle made by the incirlent beam with the } \\
\text { sample surface }\end{array}$ \\
\hline s. & $\begin{array}{l}\text { The angle made by the emergent beam with the } \\
\text { sample surface }\end{array}$ \\
\hline$\lambda_{\mathrm{m}}$ & : The short wavelength limit of the primary $x$-rays \\
\hline$i_{A}$ & : The wavelength of element $A$ absorption edge \\
\hline$w_{A}$ & : The weight fraction of element $A$ in the sample \\
\hline$p$ & : The density of sample \\
\hline$f_{11}(\lambda)$ & $\begin{array}{l}\text { : The linear absorption coefficient of sample for the } \\
\text { incident wavelength }(\lambda)\end{array}$ \\
\hline$\because A$ & $\begin{array}{l}\text { : The linear absorption coefficicnt of sample for the } \\
\text { characteristic spectrum of element } A\end{array}$ \\
\hline$\|_{0} A(\lambda)$ & $\begin{array}{l}\text { : The lincar absorption coefficient of element } A \text { for } \\
\text { the incident wavelength }(\lambda)\end{array}$ \\
\hline$K_{\mathrm{A}}$ & : The absorption edge jump-ratio of element $A$ \\
\hline$(m \mathrm{~A}$ & : The fluorescent yield of element $A$ \\
\hline$R_{\mathrm{A}}$ & $\begin{array}{l}\text { The fraction of the characteristic spectrum of cle- } \\
\text { ment } A \text { in the characteristic } x \text { ray series }\end{array}$ \\
\hline
\end{tabular}

Table 1 Notations used in the equation (1)
効エネルギーが試料の組成により敏感に変わるので11, 広く組成の変化与るものを同じやり方で取り扱うには， これらの方法はいずれも難点があった。

ところがこれらと前後して, X線管球からの一次X線 の強度分析が実测され8)，これを利用して，式 (1) から 諳算により定量分析が行われ成功した9)10). 更に，一 次 $\mathrm{X}$ 線の寄与について 理論的考察を行った交献も現れ た11) 13). 中でも，Tertian"1) は，一次 X 線の強度分布 に一つの “Analytical equivalent wavelength”があ り，これは測定元素ごとに一定であるが，試料を構成す る他元素による吸収端が測定元素のスペクトルの吸收端 より知波展側にある場合には，この“Analytical equivalent wavelength”は移動与ること先指摘している.

藷者は，一次X線の強度分布芴できるだけ考虑に入れ た簡単で新しい方法しして，管球からの一次X線を数本 のスペクトルと仮定して，それぞれの寄与率 …（1）在式（1）に導入して単純化し, 定荲分析它 行うオ法在検討した。この方法によれば，組 成の様々な僛知試料数点を用い，元素ごとに 一次X線寄与率と年数項学求めておくことにより, 標汻 化された日管分析業務のラインにのらない異種試料の分 析を行うことが可能となる。

$2 \mathrm{X}$ 線スペクトル強度式への

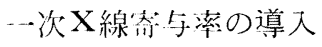

Fig. 1 に示すように, 管球加の一次X線を (1) 短 波全領域におけ石制動ふく射の最高強度位置付近，(2)

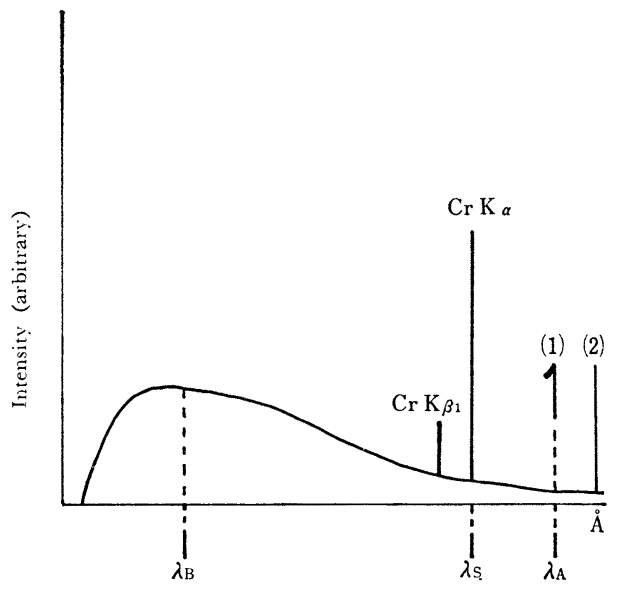

Fig. 1 Imaginary spectra $\left(\lambda_{\mathrm{B}}, \lambda_{\mathrm{S}}, \lambda_{\mathrm{A}}\right)$ of primary radiation from the $\mathrm{x}$-ray tube $(\mathrm{Cr}$-target) (1) Absorption edge corresponding to a spectrum to he measured. (2) A spectrum to be measured. 
管球の対㓌極の特性X線スペクトル位置（例えば，クロ ム対陰極では, $\mathrm{CrK}_{\alpha_{1}}$, タングステン対陰極では, $\mathrm{WL}_{\alpha_{1}}$ または $\left.\mathrm{WL}_{\beta_{1}}\right)$ ，及び (3) 測定成分元素のスペクトルに 対応する吸収端位置, などにおける単色スペクトルと 仮定し，それぞれの波長を $\lambda_{\mathrm{B}}, \lambda_{\mathrm{S}}, \lambda_{\mathrm{A}}$ とする。これら のスペクトル位置における一次 $\mathrm{X}$ 線の寄与率を, $c\left(\lambda_{\mathrm{B}}\right)$, $c\left(\lambda_{\mathrm{S}}\right), c\left(\lambda_{\mathrm{A}}\right)$ として, 式 (1) を次のように単純化した.

$$
\begin{aligned}
I_{\mathrm{A}}= & g_{\mathrm{A}} \cdot W_{\mathrm{A}} \frac{c\left(\lambda_{\mathrm{B}}\right) \cdot \mu_{0}^{\mathrm{A}}\left(\lambda_{\mathrm{B}}\right) / \rho}{\left(\mu_{0}\left(\lambda_{\mathrm{B}}\right) / \rho \cdot \operatorname{cosec} \phi_{1}+\mu_{\mathrm{A}} / \rho \cdot \operatorname{cosec} \phi_{2}\right.} \\
& +\frac{c\left(\lambda_{\mathrm{S}}\right) \cdot \mu_{0}^{\mathrm{A}}\left(\lambda_{\mathrm{S}}\right) / \rho}{\mu_{0}\left(\lambda_{\mathrm{S}}\right) / \rho \cdot \operatorname{cosec} \phi_{1}+\mu_{\mathrm{A}} / \rho \cdot \operatorname{cosec} \phi_{2}} \\
& +\frac{c\left(\lambda_{\mathrm{A}}\right) \cdot \mu_{0}^{\mathrm{A}}\left(\lambda_{\mathrm{A}}\right) / \rho}{\mu_{0}\left(\lambda_{\mathrm{A}}\right) / \rho \cdot \operatorname{cosec} \phi_{1}+\mu_{\mathrm{A}} / \rho \cdot \operatorname{cosec} \phi_{2}}
\end{aligned}
$$

$$
\text { ここで, } c\left(\lambda_{\mathrm{B}}\right)+c\left(\lambda_{\mathrm{S}}\right)+c\left(\lambda_{\mathrm{A}}\right)=1,
$$

$g_{\mathrm{A}}$ : 測定成分元素Aのスペクトル，測定条件

$$
\text { などにより決まる定数 }
$$

である.

目的成分元素の測定スペクトルに対応する吸収端波長 が，管球からの特性X線の波長より短波長側にある場合
には, $c\left(\lambda_{\mathrm{S}}\right)=0$, となる。

そこで各元素に関して，できるだけ組成の異なる既知 試料数点についてスペクトル強度を測定し, 式（2）の 定数項： $g_{\mathrm{A}}$ が試料間で一定となるように, $c\left(\lambda_{\mathrm{B}}\right), c\left(\lambda_{\mathrm{S}}\right)$, $c\left(\lambda_{\mathrm{A}}\right)$ を決めればよい。

\section{3 実験及び結果}

\section{1 試料及び測定条件}

試料の測定面は, 均質, 平滑であることを条件とし， Table 2 のような金属試料を用意した. 測定に際して, エメリーペーパ 120 で研摩し, 測定面積は $18 \mathrm{~mm} \phi$ と した.

装置としては，理学電機社製のガイガーフレックス に, Philips 社製のタングステンまたはクロム対院極 X 線管球を使用した. 測定条件を Table 3 に示す.

\section{2 測定結果}

\begin{tabular}{|c|c|c|c|c|c|c|c|c|c|}
\hline Sample & $\underset{\text { alloy }}{\mathrm{Mn}, \mathrm{Cu}}$ & $\begin{array}{c}\text { Al basea) } \\
\text { alloy }\end{array}$ & $\begin{array}{l}\text { Al baseb) } \\
\text { alloy }\end{array}$ & $\begin{array}{c}\text { Cu base }) \\
\text { alloy }\end{array}$ & $\begin{array}{l}\text { Al, Ti } \\
\text { alloy }\end{array}$ & $\begin{array}{c}\mathrm{Ti}, \mathrm{Cu} \\
\text { alloy }\end{array}$ & $\begin{array}{c}\text { Stainless } \\
\text { steel }\end{array}$ & $\begin{array}{l}\mathrm{P}, \mathrm{Sn} \\
\text { alloy }\end{array}$ & $\begin{array}{l}\text { White } \\
\text { metal }\end{array}$ \\
\hline $\mathrm{Mg}$ & & 0.43 & 0.01 & & & & & & \\
\hline $\mathrm{Al}$ & & remainder & remainder & & 94.24 & & & & \\
\hline $\mathrm{Si}$ & & 1.69 & 7.74 & & 0.06 & 0.02 & 1.19 & & \\
\hline $\mathrm{P}$ & & & & & & & & 5.00 & \\
\hline $\mathrm{Ti}$ & & 0.07 & 0.20 & & 5.10 & 24.10 & 0.34 & & \\
\hline $\mathrm{Cr}$ & & 0.38 & 0.01 & & & & 18.35 & & \\
\hline $\mathrm{Mn}$ & 24.78 & 0.76 & 1.34 & & & & 0.53 & & \\
\hline $\mathrm{Fe}$ & 0.09 & 3.70 & 0.20 & & 0.15 & 0.30 & remainder & & \\
\hline $\mathrm{Ni}$ & & 0.20 & 0.13 & 0.03 & & & 9.11 & & \\
\hline $\mathrm{Cu}$ & 75.13 & 3.00 & 1.50 & 59.08 & & 75.57 & 0.19 & & 5.92 \\
\hline $7 \mathrm{n}$ & & 3.70 & 1.12 & 40.10 & & & & & \\
\hline $\mathrm{Nb}$ & & & & & & & 0.60 & & \\
\hline Mo & & & & & & & 0.43 & & \\
\hline $\mathrm{Sn}$ & & 0.31 & 0.52 & 0.74 & & & & 95.00 & 85.30 \\
\hline $\mathrm{Sb}$ & & & & & & & & & 8.58 \\
\hline $\mathrm{Pb}$ & & 0.32 & 0.03 & 0.03 & & & & & \\
\hline
\end{tabular}

Table 2 に示すような金䦨試料に関して, $\mathrm{CuK}_{\alpha}$, $\mathrm{FeK}_{\boldsymbol{\alpha}}, \mathrm{TiK}_{\boldsymbol{\alpha}}, \mathrm{SnL}_{\boldsymbol{\alpha}}$ を測定し, 一次X線仮想スペクト ル位置においてあらかじめ仮定した寄与率に基づき, 式

Table 2 Chemical composition of metallic samples (\%)

\begin{tabular}{|c|c|c|c|c|}
\hline & $\mathrm{CuK}_{\alpha}$ & $\operatorname{FeK}_{\alpha}$ & $\operatorname{TiK}_{\alpha}$ & $\operatorname{SnL} \alpha$ \\
\hline $\mathrm{X}$-Ray tube $(\mathrm{kV})$ & $\begin{array}{l}\text { W-30, } 20 \\
\text { Cr-50, } 40,30,20\end{array}$ & $\begin{array}{l}\mathrm{W}-40,20 \\
\mathrm{Cr}-30\end{array}$ & $\begin{array}{l}\mathrm{W}-40,30 \\
\mathrm{Cr}-30\end{array}$ & \multirow{6}{*}{$\begin{array}{l}\text { Cr-30 } \\
\text { EDDT } \\
\text { Gas flow type } \\
\text { proportional counter }\end{array}$} \\
\hline Crystal & $\mathrm{LiF}$ & $\mathrm{LiF}$ & LiF & \\
\hline Detector & \multicolumn{2}{|c|}{ Scintillation counter } & & \\
\hline X-Ray path & \multicolumn{2}{|c|}{ Vacuum } & & \\
\hline Counting method & \multicolumn{2}{|c|}{ Fixed time, $20 \mathrm{~s}$} & & \\
\hline Exposed area & \multicolumn{2}{|c|}{$18 \mathrm{~mm} \dot{\varphi}$} & & \\
\hline
\end{tabular}

a) Appex standards, SM9; b) Appex standards, V; c) NBS, C1106; d) NBS, D846; Electrolytic copper, electrolytic iron, titanium metal $(99.70 \%$ ) and tin foil (with the thickness of $40 \mu \mathrm{m}$ ) were also used.

Table 3 Operating conditions 
（2）によりそれぞれ定数項 $: g_{\mathrm{Cu}}, g_{\mathrm{Fe}}, g_{\mathrm{Ti}}, g_{\mathrm{Sn}}$ を計 算し,試料間の变動を調べた。銅について,クロム対陰㮌 X線管球の電厅:を变化させつつ求めた場合を Table 4 に示す. 銅, 鉄, チタン, スズについて, クロム刘陰極X線 管球により求めた結果を Table 5 に, 銅, 鉄, チタンにつ いて，タングステン対陰極X線管球により求めた結果を Table 6 に示す. 得られた定数項 $: g_{\mathrm{A}}$ の試料間に抢け る変動(標準偏差率で示す)が最小となるような一次X線

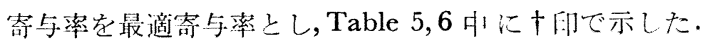

\section{3 一次 $\mathbf{X}$ 線強度分布と寄与率との関係}

Gilfrich らにより求められたタングステン刘陰㢦，及

Table 4 Assumed relative contribution of primary radiation and $g_{\mathrm{Cu}}$ (Effect of applied voltage for the Cr-target)

\begin{tabular}{|c|c|c|c|c|}
\hline \multirow{3}{*}{$\begin{array}{l}\text { Applied } \\
\text { voltage } \\
\text { and } \\
\text { current, } \\
\mathrm{kV}, \mathrm{mA}\end{array}$} & \multicolumn{4}{|c|}{$c\left(\lambda_{\mathrm{B}}\right)^{\mathrm{a})}$} \\
\hline & 0.6 & \multicolumn{3}{|c|}{$c\left(\lambda_{\mathrm{d}}\right)^{\mathrm{b})}$} \\
\hline & 0.4 & 0.3 & 0.2 & 0.1 \\
\hline 5) $4\left\{\begin{array}{l}g_{\mathrm{Cu}} \\
\sigma \%\end{array}\right.$ & $\begin{array}{c}16.516 \times 10^{5} \\
4.8\end{array}$ & $\begin{array}{c}18.865 \times 10^{5} \\
3.8\end{array}$ & $\begin{array}{c}22.097 \times 10^{5} \\
4.0\end{array}$ & $\begin{array}{c}26.763 \times 10^{5} \\
8.3\end{array}$ \\
\hline 40) $4\left\{\begin{array}{l}g_{\mathrm{Cu}} \\
\sigma \%\end{array}\right.$ & $\begin{array}{c}12.535 \times 10^{5} \\
5.2\end{array}$ & $\begin{array}{c}14.315 \times 10^{5} \\
4.0\end{array}$ & $\begin{array}{c}16.76 .5 \times 10^{5} \\
3.8\end{array}$ & $\begin{array}{c}20.299 \times 10^{5} \\
7.9\end{array}$ \\
\hline 30. $4\left\{\begin{array}{l}g_{\mathrm{Cu}} \\
\sigma \%\end{array}\right.$ & $\begin{array}{c}8.104 \times 105 \\
5.4\end{array}$ & $\begin{array}{c}9.255 \times 10^{5} \\
4.3\end{array}$ & $\begin{array}{c}10.839 \times 10^{3} \\
4.2\end{array}$ & $\begin{array}{c}13.125 \times 10^{5} \\
8.1\end{array}$ \\
\hline $20+\left\{\begin{array}{l}g_{\mathrm{Cu}} \\
\sigma \%\end{array}\right.$ & $\begin{array}{c}3.437 \times 10^{5} \\
4.7\end{array}$ & $\begin{array}{c}3.927 \times 10^{5} \\
3.8\end{array}$ & $\begin{array}{c}4.602 \times 10^{5} \\
5.3\end{array}$ & $\begin{array}{c}5.577 \times 10^{5} \\
9.2\end{array}$ \\
\hline
\end{tabular}

びクロム対陰極X線管球からの一次 $\mathrm{X}$ 線強度分布8)14)

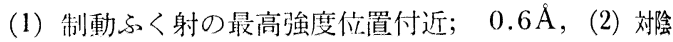

Table 5 Assumed relative contribution of primary radiation and $g_{\mathrm{Cu}}, g_{\mathrm{Fe}}, g_{\mathrm{Ti}}$ and $g_{\mathrm{Sn}}$ (Cr-target : $30 \mathrm{kV}-10 \mathrm{~mA}$ )

\begin{tabular}{|c|c|c|c|c|c|}
\hline Element & $c\left(\lambda_{\mathrm{B}}\right)^{a)}$ & $c\left(\lambda_{\mathrm{S}}\right)^{\mathrm{b})}$ & $\left.c\left(\lambda_{\mathrm{A}}\right) \mathrm{c}\right)$ & $g_{\mathrm{A}}$ & $\sigma(\%)$ \\
\hline \multirow{7}{*}{ Cu } & 0 & & 1 & $11.721 \times 10^{5}$ & 7.5 \\
\hline & 0.4 & & 0.6 & $16.290 \times 10^{5}$ & 5.7 \\
\hline & 0.5 & & 0.5 & $18.072 \times 10^{5}$ & 5.0 \\
\hline & 0.6 & & 0.4 & $20.311 \times 10^{5}$ & 4.0 \\
\hline & 0.65 & & 0.35 & $21.663 \times 10^{5}$ & 3.3 \\
\hline & +0.7 & & 0.3 & $23.218 \times 10^{5}$ & 3.1 \\
\hline & 1 & & 0 & $42.160 \times 10^{5}$ & 15.7 \\
\hline \multirow{7}{*}{$\mathrm{Fe}$} & 0 & & 1 & $7.277 \times 10^{5}$ & 15.0 \\
\hline & 0.4 & & 0.6 & $10.850 \times 10^{5}$ & 11.2 \\
\hline & 0.5 & & 0.5 & $12.380 \times 10^{5}$ & 9.7 \\
\hline & 0.7 & & 0.3 & $17.315 \times 10^{5}$ & 5.5 \\
\hline & 0.75 & & 0.25 & $19.260 \times 10^{5}$ & 4.4 \\
\hline & +0.8 & & 0.2 & $22.452 \times 10^{5}$ & 4.0 \\
\hline & 1 & & 0 & $47.235 \times 10^{5}$ & 12.2 \\
\hline \multirow{4}{*}{$\mathrm{Ti}$} & to & & 1 & $18.984 \times 10^{5}$ & 7.2 \\
\hline & 0.05 & & 0.95 & $19.914 \times 10^{3}$ & 7.4 \\
\hline & 0.1 & & 0.9 & $20.941 \times 10^{5}$ & 7.4 \\
\hline & 0.2 & & 0.8 & $23.349 \times 10^{5}$ & 7.6 \\
\hline \multirow{11}{*}{$\mathrm{Sn}_{\mathrm{n}}$} & 0 & 0 & 1 & $12.905 \times 10^{5}$ & 14.6 \\
\hline & 0 & 1 & () & $16.662 \times 10^{5}$ & 10.0 \\
\hline & 0.2 & 0.75 & 0.05 & $19.790 \times 10^{5}$ & 9.8 \\
\hline & 0.5 & 0.25 & 0.25 & $27.634 \times 10^{5}$ & 11.1 \\
\hline & 0.5 & 0.45 & 0.05 & $30.445 \times 10^{5}$ & 9.0 \\
\hline & 0.6 & 0.35 & 0.05 & $36.733 \times 10^{5}$ & 8.6 \\
\hline & 0.7 & 0.3 & 0 & $48.052 \times 10^{5}$ & 6.9 \\
\hline & 0.8 & 0.15 & 0.05 & $62.632 \times 10^{5}$ & 6.9 \\
\hline & +0.8 & 0.2 & 0 & $65.934 \times 10^{5}$ & 5.8 \\
\hline & 0.9 & 0.1 & 0 & $10.538 \times 10^{5}$ & 6.1 \\
\hline & 1 & 0 & 0 & $28.704 \times 10^{4}$ & 22.3 \\
\hline
\end{tabular}

a) $\lambda_{\mathrm{B}}=0.6 \AA$, b) $\lambda_{\mathrm{S}}=2.2896 \AA$; the wavelength of $\mathrm{CrK}_{a_{1}}$, c) For $\mathrm{Cu} \lambda_{\mathrm{A}}=1.3804 \AA$, for $\mathrm{Fe} \lambda_{\mathrm{A}}=1.7433 \AA$; the wavelength of FeK absorption edge, for $\mathrm{Ti} \lambda_{\mathrm{A}} 2.4973 \AA$; the wavelength of 'TiK absorption edge; $\fallingdotseq \lambda_{\mathrm{S}}$, and for $\mathrm{Sn} \lambda_{\mathrm{A}} \cdot 3.1557 \AA$; the wavelength of SnI.III absorption edge.

Table 6 Assumed relative contribution of primary radiation and $g_{\mathrm{Cu}}, g_{\mathrm{Fe}}$ and $g_{\mathrm{Ti}}$ (W-target)

\begin{tabular}{|c|c|c|c|c|c|c|c|}
\hline \multirow[t]{2}{*}{ Element } & \multirow[t]{2}{*}{$\left.c\left(\lambda_{\mathrm{B}}\right)^{\mathrm{a}}\right)$} & \multirow[t]{2}{*}{$\left.c\left(\lambda_{\mathrm{S}}\right)^{\mathrm{b}}\right)$} & \multirow[t]{2}{*}{$c\left(\lambda_{\mathrm{A}}\right)^{\mathrm{e}}$} & \multicolumn{2}{|c|}{$g_{\mathrm{A}}$} & \multicolumn{2}{|c|}{$\sigma(\%)$} \\
\hline & & & & $30 \mathrm{kV}-2 \mathrm{~mA}$ & $20 \mathrm{kV}-4 \mathrm{~mA}$ & $30 \mathrm{kV}-2 \mathrm{~mA}$ & $20 \mathrm{kV}-4 \mathrm{~mA}$ \\
\hline C.u & $\begin{array}{l}0.2 \\
0.29 \\
0.4 \\
0.5 \\
+0.6 \\
0.7 \\
0\end{array}$ & $\begin{array}{l}0.7 \\
0.66 \\
0.5 \\
0.45 \\
0.35 \\
0.25 \\
0\end{array}$ & $\begin{array}{l}0.1 \\
0.05 \\
0.1 \\
0.05 \\
0.05 \\
0.05 \\
1\end{array}$ & $\begin{array}{r}12.552 \times 10^{5} \\
13.614 \times 10^{5} \\
14.812 \times 10^{5} \\
16.487 \times 10^{5} \\
18.390 \times 10^{5} \\
20.954 \times 10^{5} \\
3.095 \times 10^{4}\end{array}$ & $\begin{array}{r}10.022 \times 10^{5} \\
10.870 \times 10^{5} \\
11.827 \times 10^{5} \\
13.164 \times 10^{5} \\
14.677 \times 10^{5} \\
16.723 \times 10^{5} \\
2.552 \times 10^{4}\end{array}$ & $\begin{array}{r}6.2 \\
6.2 \\
4.4 \\
4.5 \\
4.2 \\
4.4 \\
34.9\end{array}$ & $\begin{array}{r}6.1 \\
6.1 \\
4.4 \\
4.5 \\
4.3 \\
4.5 \\
37.4\end{array}$ \\
\hline & & & & $40 \mathrm{kV}-2 \mathrm{~mA}$ & $20 \mathrm{kV} \cdot 4 \mathrm{~mA}$ & $40 \mathrm{kV}-2 \mathrm{~mA}$ & $20 \mathrm{kV}-4 \mathrm{~mA}$ \\
\hline $\mathrm{Fe}$ & $\begin{array}{l}0.1 \\
0.21 \\
0.4 \\
0.5 \\
+0.6 \\
0.7 \\
0.8\end{array}$ & $\begin{array}{l}0.8 \\
0.73 \\
0.55 \\
0.45 \\
0.35 \\
0.25 \\
0.15\end{array}$ & $\begin{array}{l}0.1 \\
0.06 \\
0.05 \\
0.05 \\
0.05 \\
0.05 \\
0.0 .5\end{array}$ & $\begin{array}{l}14.086 \times 10^{5} \\
15.635 \times 10^{5} \\
19.076 \times 10^{5} \\
21.561 \times 10^{5} \\
24.806 \times 10^{5} \\
29.237 \times 10^{5} \\
35.682 \times 10^{5}\end{array}$ & $\begin{array}{r}7.914 \times 10^{5} \\
8.784 \times 10^{5} \\
10.715 \times 10^{5} \\
12.109 \times 10^{5} \\
13.930 \times 10^{5} \\
16.415 \times 10^{5} \\
20.028 \times 10^{5}\end{array}$ & $\begin{array}{l}8.2 \\
7.2 \\
5.5 \\
4.6 \\
3.8 \\
4.0 \\
6.3\end{array}$ & $\begin{array}{l}8.8 \\
7.8 \\
6.0 \\
4.8 \\
3.7 \\
3.4 \\
5.6\end{array}$ \\
\hline & & & & $40 \mathrm{kV}-10 \mathrm{~mA}$ & $30 \mathrm{kV}-10 \mathrm{~mA}$ & $40 \mathrm{kV}-10 \mathrm{~mA}$ & $30 \mathrm{kV}-10 \mathrm{~mA}$ \\
\hline $\mathrm{Ti}$ & $\begin{array}{c}0 \\
0 \\
+0.1 \\
0.1 \\
0.2 \\
0.3 \\
0.5 \\
0.7\end{array}$ & $\begin{array}{l}0 \\
1 \\
0.8 \\
0.5 \\
0.7 \\
0.65 \\
0.45 \\
0.25\end{array}$ & $\begin{array}{l}1 \\
0 \\
0.1 \\
0.4 \\
0.1 \\
0.05 \\
0.05 \\
0.05\end{array}$ & $\begin{array}{l}10.462 \times 10^{5} \\
21.073 \times 10^{5} \\
20.820 \times 10^{5} \\
16.274 \times 10^{5} \\
22.761 \times 10^{5} \\
26.662 \times 10^{5} \\
34.130 \times 10^{5} \\
47.446 \times 10^{5}\end{array}$ & $\begin{array}{r}7.088 \times 10^{5} \\
14.468 \times 10^{5} \\
14.302 \times 10^{5} \\
11.193 \times 10^{5} \\
15.634 \times 10^{5} \\
18.308 \times 10^{5} \\
23.432 \times 10^{5} \\
32.564 \times 10^{5}\end{array}$ & $\begin{array}{r}11.7 \\
10.4 \\
8.9 \\
9.7 \\
9.0 \\
10.2 \\
11.0 \\
12.5\end{array}$ & $\begin{array}{r}11.1 \\
9.0 \\
7.8 \\
10.1 \\
7.9 \\
8.8 \\
9.6 \\
11.1\end{array}$ \\
\hline
\end{tabular}

a) $\lambda_{\mathrm{B}} 0.6 \AA$, b) for $\mathrm{Cu} \lambda_{\mathrm{S}} \cdot 1.2817 \AA$; the wavelength of W1. $\beta_{1}$, for Fe and $\mathrm{Ti} \lambda_{\mathrm{S}} 1.4763 \AA$; the wavelength of WI.a, c) For Cu $\lambda_{\mathrm{A}} 1.3804 \AA$, for Fe $\lambda_{\mathrm{A}}-1.7433 \AA$ and for Ti $\lambda_{\mathrm{A}}-2.4973 \AA$ 
極元素の特性 $\mathrm{X}$ 線スペクトル仙置; $\mathrm{WL}_{\beta_{1}}$ または $\mathrm{WL}_{\boldsymbol{\alpha}_{1}}$ 及び $\mathrm{CrK}_{\alpha_{1}}$ ，(3) 測定成分元素のスペクトルに対応寸る 吸收端位置，までそれぞれ積分し百分率で示したものと， Table 5, 6 に示した最適寄与率を比較すると, Table 7 のようになる。最適寄与率と積分強度とは必ずしも一致 していない、すなわち，チタンの場合を除いて，短波歪 側の制動ふく射の寄与は，Gilfrich らによる強度分犱加 ら求めた積分強度より，はるかに大きい值となった。 ク 口ム対除枸 $\mathrm{X}$ 線管球による $\mathrm{TiK}_{\boldsymbol{\alpha}}$ の測定の場命には, 管球からの特性 X 線; $\mathrm{CrK}_{\boldsymbol{\alpha}}$ が，TiK 吸収端のわずか に短波長側にあるために，他の元素の場合に比較して，
特にチタンに対して一次X線源が単色光として作用した ものと推定される.

Table 4，6 の結果から， $\mathrm{X}$ 線管球の印加電厅:の違い による最適寄与率の変化は大きくないものと推定され る.

\section{4 定量分析への応用}

測定したスペクトル強度から計算によって会有量 $W_{\mathrm{A}}$ を求めるためには，次の式9に含有量既知の標潐試料ま たは純物質とのスペクトル強度比; $r_{\mathrm{A}}{ }^{\mathrm{m}}$ ，推定含有量； $W_{\mathrm{A}}{ }^{\mathrm{E}}$, 推定組成により式 (2) から計算した未知試料と

Table 7 Integrated intensity of primary radiation and optimum relative contribution

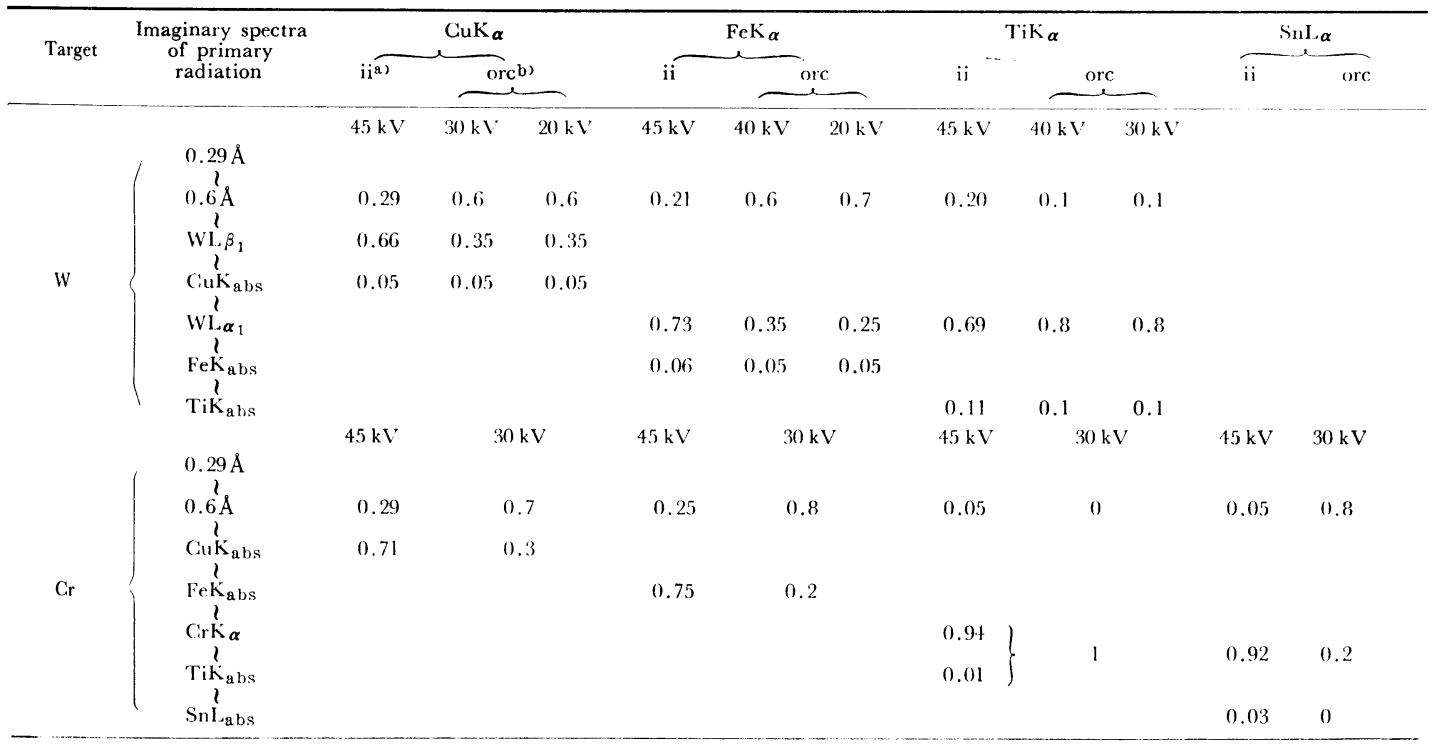

a) Integrated intensity of primary radiation; b) Optimum relative contribution

Table 8 Examples of analysis

\begin{tabular}{|c|c|c|c|c|c|c|c|c|}
\hline \multirow{3}{*}{ Sample } & \multirow{3}{*}{ Element } & \multirow{3}{*}{$\begin{array}{c}\text { Chemical } \\
\text { analysis } \\
(\%)\end{array}$} & \multirow{3}{*}{$r_{\mathrm{A}}{ }^{\mathrm{m}}$} & \multicolumn{3}{|c|}{ This method } & & \\
\hline & & & & \multirow{2}{*}{$\begin{array}{l}W_{\mathrm{A}} \\
(\%)\end{array}$} & \multirow{2}{*}{$\begin{array}{c}\text { Target } \\
(\mathrm{kV}-\mathrm{mA})\end{array}$} & \multicolumn{3}{|c|}{ Relative contribution } \\
\hline & & & & & & $c\left(\lambda_{\mathrm{B}}\right)$ & $c\left(\lambda_{\mathrm{s}}\right)$ & $c\left(\lambda_{\mathrm{A}}\right)$ \\
\hline Ferro-copper & $\begin{array}{l}\mathrm{Cu} \\
\mathrm{Fe} \\
\mathrm{Si}\end{array}$ & $\begin{array}{r}49.78 \\
49.30 \\
0.12\end{array}$ & $\begin{array}{l}0.3172 \\
0.6304\end{array}$ & $\begin{array}{l}49.59 \\
49.36\end{array}$ & $\mathrm{Cr}$, ,30 10 & $\begin{array}{l}0.7 \\
0.8\end{array}$ & & $\begin{array}{l}0.3 \\
0.2\end{array}$ \\
\hline $\begin{array}{l}\text { Aluminum } \\
\text { copper } \\
\text { alloys }\end{array}$ & $\begin{array}{l}\mathrm{Cu} \\
\mathrm{Fe} \\
\mathrm{Al} \\
\mathrm{Clu} \\
\mathrm{Fe} \\
\mathrm{Al}\end{array}$ & $\begin{array}{c}49.00 \\
0.20 \\
\text { remainder } \\
49.00 \\
0.20 \\
\text { remainder }\end{array}$ & $\begin{array}{l}0.6988 \\
0.0055\end{array}$ & $\begin{array}{r}49.13 \\
0.30\end{array}$ & $\mathrm{Cr},{ }_{11}^{30 \cdots 10}$ & $\begin{array}{l}0.7 \\
0.8\end{array}$ & 0.35 & $\begin{array}{l}0.3 \\
0.2\end{array}$ \\
\hline $\begin{array}{l}\text { Copper base } \\
\text { alloy }\end{array}$ & $\begin{array}{l}\mathrm{Cu} \\
\mathrm{Fe} \\
\mathrm{Sn} \\
\mathrm{Zn}\end{array}$ & $\begin{array}{c}96.45 \\
0.02 \\
0.03 \\
\text { remainder }\end{array}$ & $\begin{array}{l}0.9609 \\
0.0016 \\
0.0008\end{array}$ & $\begin{array}{r}95.52 \\
0.09 \\
0.07\end{array}$ & $\begin{array}{l}\mathrm{Cr}, 30-10 \\
\mathrm{Cr}, 30-20\end{array}$ & $\begin{array}{l}0.7 \\
0.8 \\
0.8\end{array}$ & 0.2 & $\begin{array}{l}0.3 \\
0.2 \\
0\end{array}$ \\
\hline White metal & $\begin{array}{l}\mathrm{Cu} \\
\mathrm{Sn} \\
\mathrm{Sb} \\
\mathrm{Pb}\end{array}$ & $\begin{array}{r}0.57 \\
12.80 \\
14.10 \\
72.20\end{array}$ & $\begin{array}{l}0.0048 \\
0.0490 \\
0.7792\end{array}$ & $\begin{array}{r}0.97 \\
12.49\end{array}$ & $\begin{array}{ll}\mathrm{Cr}, & 30-10 \\
\mathrm{Cr}, & 30-20\end{array}$ & $\begin{array}{l}0.7 \\
0.8\end{array}$ & 0.2 & $\begin{array}{l}0.3 \\
0\end{array}$ \\
\hline
\end{tabular}


標準試料との強度比； $r_{\mathrm{A}}$ などを代入すればよい.

$$
W_{\mathrm{A}}=W_{\mathrm{A}}^{\mathrm{E}} \cdot r_{\Lambda}^{\mathrm{m}} / r_{\mathrm{A}}
$$

このようにして, 試料を構成する全元素について $W_{\Lambda}$ を求め, これを加え合わせて 1 に規格化し各元素の $W_{\mathrm{A}} \mathrm{E}$ を求める． $W_{\mathrm{A}}$ と $W_{\mathrm{A}} \mathrm{E}^{\mathrm{E}}$ とが，1\%の範囲内で一致する まで繰り返し近似計算を行っていく.

このようにして定量計算した例を, Table 8 に示す. ここでは, 一次X線寄与率, 及び定数 $g_{\mathrm{A}}$ の求められて いない元素については, 純元素とのスペクトル強度比; $r_{\mathrm{A}}{ }^{\mathrm{m}}$ をとのまま推定含有叟； $W_{\mathrm{A}}{ }^{\mathrm{E}}$ と与るか，あるいは， その他の元素の推定含有最を1から筧し引いた残部を推 定含有量として計算した.

Table 8 から, 含有量が $1 \%$ 末満の條については誤 差が大きいが，含有量が大きいものについては，この方 法は十分使用可能であることが分かった。

\section{4 考察}

以上，管球からの一次X線を，主要強度伦置（制動子 く射の最高強度位置, 刘陰極の特性 $\mathrm{X}$ 線スペクトル位 置, 及び測定元素のスペクトルの吸収端位置）に抢ける 単色スペクトルと仮定し，それぞれの寄与率をスペクト ル強度式に導入した。これを利用することにより，均質 試料によっていろいろな元素の $g_{\mathrm{A}}$ と一次X線寄与率を 前もって求めておけば，類似組成の標準試料群による検 量線がなくても，逐次近似計算により定量分析が可能と なる. 式（1)，(2) は，吸収補正のみで励起効果の補正: 項は含まれていないから，測定成分元素に対して励起効 果を与える元素が試料中に含まれている場合には，誤差 の原因となる. 非常に精度の高い分析を必要とするので なければ，日常分析作業のラインにのらない異質な試料 の分析に，このような力法は利用度が高いものと考えら れる。

終わりにこの研究を行うにあたり，X線管球からの X線強度分布に関するデータを御提供くださった Dr. W. Gilfrich に深謝致します.

\section{交献}

1) E. Gillam, H. T. Heal : Brit. J. Appl. Phys., 3, 353 (1952).

2) J. Sherman : Spectrochim. Acta, 7, 283 (1955).

3) R. V. Mège : Anal. Chem., 41, 42 (1969).

4) R. Tertian : Spectrochim. Acta, 23B, 305 (1968).

5) A. Strasheim, M. P. Brandt : ibid., 23B, 183
(1968) .

6) H. Ebel : Advances in X-ray Analysis, 13, 68 (1970).

7) D. A. Stephenson : Anal. Chem., 43, 1761(1971).

8) W. Gilfrich, L. S. Birks : ibid., 40, 1077 (1968).

9) J. W. Criss, L. S. Birks : ibid., 40, 1080 (1968).

10) 白岩俊男, 藤野允克 : 住友金属, 19, 202(1967).

11) R. Tertian : Spectrochim. Acta, 26B, 71 (1971).

12) H. Ebel, et al. : ibid., 25B, 83 (1970).

13) H. Bent : ibid., 27B, 47 (1972).

14) W. Gilfrich : 私信.

$$
\text { is }
$$

Contribution of the primary radiation to the fluorescent $x$-ray intensity and its application in analytical chemistry. Yoko ISHII (Railway Technical Research Institute, Hikari-cho, Kokubunji-shi, Tokyo)

For the analysis of the samples which cannot be dealt with routinely or for which calibration curves are not yet available, a formula of the $x$-ray intensity is useful. However, the formula must be modified by taking the primary radiation from the $x$-ray tube into consideration. To do this, the continuous primary radiation was assumed to be formed of a few representative spectral lines with the wavelengths, one near the peak position of Bremssrahlung, two the one of the characteristic spectra from the target of $\mathrm{x}$-ray tube, i.e., $\mathrm{WL}_{\alpha_{1}}$ or $\mathrm{WL}_{\beta_{1}}$ in $\mathrm{W}$-target and $\mathrm{CrK}_{\alpha_{1}}$ in Cr-target, and three that of the absorption edge corresponding to the spectrum to be measured. Relative contribution of the primary radiation to the secondary radiation at each of these spectral lines was evaluated and substituted for the term of the distribution of the primary radiation. The $x$-ray intensity formula was thus simplified. If the relative contribution and the constants which depend on the spectrum of the element in question and the instrumental condition were obtained for various elements, the simplified $\mathrm{x}$-ray intensity formula is easily applicable to the quantitative analysis without the calibration curve prepared with the standard samples of similar composition. As examples, relative contribution and constants were experimentally obtained for $\mathrm{CuK}_{\alpha}$, $\mathrm{FeK}_{\alpha}, \mathrm{TiK}_{\alpha}$ and $\mathrm{SnL}_{\alpha}$, and applied to the analysis of copper alloy, aluminum alloy and white metal. Not small error was observed in the determination of the constituent less than $1 \%$, however, this method is simple and useful for the determination of the component higher than $1 \%$.

(Received Aug. 30, 1974)

\section{Keywords}

Fluorescent $\mathrm{x}$-ray intensity formula

Relative contribution of primary radiation 